\title{
Studi Pembentukan Huruf Font Dengan Kurva Bezier
}

\author{
Agung Haryono, S.Kom., M.Kom. \\ Jurusan Teknologi Informasi \\ Institut Sains Terapan dan Teknologi Surabaya \\ Jl. Ngagel Jaya Tengah 73-77, Surabaya \\ andreasagung88@gmail.com
}

\begin{abstract}
ABSTRAK
Kurva bezier (baca : bes-ee-ay) merupakan sebuah kurfa parametrik yang sering diterapkan pada komputer grafis dan dalam bidang-bidang berhubungan lainnya. Kurva bezier sangat dikenal karena kemampuannya untuk menghasilkan kurva yang halus.

Penelitian ini bertujuan untuk mengetahui peran kurva bezier dalam pembentukan huruf-huruf Font dan mencari perbedaan peran kurva bezier dalam pembentukan Font TrueType dan Font PostScript.

Sedangkan manfaat dari penelitian ini adalah mengenalkan pada masyarakat cara kerja dan peran kurva bezier dalam pembentukan huruf-huruf Font.

Font TrueType dan font PostScript merupakan font vektor yang sama-sama menggunakan kurva bezier untuk menggambarkan kontur-kontur glyph. Font TrueType menggunakan kurva bezier kuadratik yaitu kurva bezier berordo 2, Font PostScript menggunakan kurva bezier kubik yaitu kurva bezier berordo 3.
\end{abstract}

Kata kunci : Kurva bezier, font TrueType, font PostScript.

\section{PENDAHULUAN}

Dalam dunia tipografi, Font adalah sebuah kumpulan karakter lengkap yang mempunyai satu ukuran dan gaya. Sedangkan dalam dunia komputer, Font merupakan file data elektronik yang menganduk sebuah kumpulan dari elemen penulisan ( $g l y p h$ ), karakter-karakter atau simbol-simbol. Saat ini terdapat lebih dari ratusan ribuan jenis Font di dunia. Sistem operasi ternama di dunia, Microsoft Windows, yang mampu menampung hingga 4000 Font dalam sistemnya, menggunakan TrueType sebagai format Font digital. 


\section{METODOLOGI PENELITIAN}

Telah diketahui pada latar belakang bahwa kurva bezier sangat berperan penting dalam pembentukan Font outline pada TrueType dan PostScript. Untuk mengenal lebih lanjut apa itu kurva bezier, Font TrueType dan PostScript, makan akan dijabarkan pada sub bab -sub bab dibawah ini.

\section{A. Kurva Bezier}

Pada akhir tahun 1950, komputer sudah mampu digunakan untuk membuat kalkulasi dan desain automobil. Sayangnya waktu itu tidak ada program yang mampu untuk membuat dan mewakili penggambaran kurva pada sebuah automobil secara efektif. Seorang insinyur asa Perancis yang bekerja pada Renault, Pierre Bezier, menerapkan sebuah kurva khusus untuk menyelesaikan masalah ini. Meskipun kurva ini dinamakan seperti itu, bukan berarti Pierre Bezier adalah orang yang menemukannya karena pada tahun yang sama P.De Castelju juga menerapkan kurva yang sama dalam perancangan tubuh automobil. Kurva parametrik ini telah diketahui sejak lama, namun tidak banyak orang yang mengenalnya. Baru pada tahun 1962, Pierre Bezier mempublikasikan kurva ini.

Kurva bezier terdiri dari beberapa titik pembentuknya yang berjumlah $n+1$ sehingga terdapat titik-titik $\mathrm{P}_{0}$ sampai dengan $\mathrm{P}_{\mathrm{n}}$. Titik $\mathrm{P}_{0}$ merupakan titik awal kurva dimana terdapat kurva akan berangkat daru titik tersebut dan melengkung ke arah $\mathrm{P}_{\mathrm{n}}$ dan berhenti di titik tersebut.Semua ini dilakukan dengan t sebagai presentase waktu tempuh kurva dari titik $\mathrm{P}_{0}$ dan $\mathrm{P}_{\mathrm{n}}$ yaitu dari $\mathrm{t}=0$ hingga $\mathrm{t}=1$. Jadi ketika $\mathrm{t}=0$ garis kurva berada tepat pada titik $\mathrm{P}_{0}$ dan ketika $\mathrm{t}=1$ garis kurva berada tepat pada titik $\mathrm{P}_{\mathrm{n}}$.

Perlu diketahui bahawa t bukanlah lamanya waktu yang ditempuh untuk membuat sebuah kurva. Variabel t menunjukkna seberapa jauh kurva bezier yang diwakili oleh fungsi $B(t)$ bergerak dari $P_{0}$ hingga $P_{1}$. Sebagai contoh, ketika $t=0,25$ fungsi $\mathrm{B}(\mathrm{t})$ berada pada seperempat jalan dari titik $\mathrm{P}_{0}$ ke titik $\mathrm{P}_{1}$. Adapun persamaan untuk kurva bezier ordo satu (bezier linier) adalah :

$$
\mathrm{B}(t)=\mathrm{P}_{\mathrm{n}}+t\left(\mathrm{P}_{1}-\mathrm{P}_{\mathrm{n}}\right)=(1-t) \mathrm{P}_{\mathrm{n}}+t \mathrm{P}_{1} . t €[0.1]
$$

Jika diperhatikan rumus-rumus kurva bezier yang berurutan dari ordo satu sampai tiga menganut kaidah segitiga pascal. Setiap tingkat ordo satu pada kurva bezier berbanding lurus dengan baris-baris segitiga Pascal yaitu setiap ordo n akan memiliki koefisienkoefisien pada paris $n+1$ pada segitiga Pascal. 


\section{B. Font}

Font merupakan salah satu bentuk seni yang dibuat hak ciptanya untuk dibeli atau dijual. Saat ini terdapat lebih dari ratusan ribuan jenis Font didunia. Seringkali dalam komputerisasi orang-orang mengatakan Font ketika istilah typeface lebih dikatakan. Contoh dari typeface antara lain Times, Courier dan Arial karena memasukkan banyak ukuran dan banyak gaya. Sedangkan contoh Font antara lain bold (cetak tebal), italic (cetak miring), bold italic (cetak miring dan tebal), underline (bergaris bawah), outline (hanya mempunyai garis luar), dan shadow (berbayangan). Dalam definisi, Font merupakan keluarga typeface, sebagai contoh Arial 12-point italic, maka itu adalah dengan ukuran 12-point bercetak miring dari typeface Arial.

Typeface telah diketahui sendiri merupakan karakter-karakter khusus dan unik yang mempunyai banyak ukuran dan banyak gaya. Dengan demikian typeface memiliki banyak Font dengan berbagai ukuran dan didsain dengan kesatuan gaya.

Terdapat tiga macam format Font pada komputer antara lain Font bitmap, outline dan stroke. Perbedaan format tersebut bergantung pada komponen-komponen dalam pembentukan Font.

\section{- Font TrueType}

TruetType merupakan Font vektor atau Font berformat outline yang digunakan pada sistem operasi Microsoft Windows dan Apple Computer. Pada Font vektor, sebuah seri dari koordinasi menggambarkan sebuah kontur karakter, jadi perubahan pengskalaan sederhana secara efektif mengecilkan atau memperbesar karakter. Sejak dikenalkan pada publik pada tahun 1991, Font TrueType telah menjadi teknologi Font yang dominan untuk digunakan sehari-hari. Karena Font TrueType tidak membutukan bahasa pencetakan khusus, Font TrueType menggantikan peran Font PostScript pada dunia percetakan.

Terdapat ribuan Font TrueType yang tersedia di dunia dan cukup banyak diantaranya yang disediakan cuma-cuma pada web. Banyak dari Font ini telah ditinjau dan diubah ke dalam sumber-sumber lain. Sementara sebagian Font dapat diproses dengan baik, pembuatan Font TrueType yang kurang baik dapat mengandung error yang dapat mengakibatkan kerusakan pada komputer. Font yang didesain secara profesional dapat menghabiskan banyak biaya namun biasanya membutuhkan hint yang cukup berat dan telah diuji pada berbagai ukuran dan sudut pada kualitas optimal. 


\section{- Font PostScript}

PostScript merupakan Font outline atau Font berbasis vektor yang mendeskripsikan karakter dengan konstruksi matematis yaitu kurva bezier. Karena dikonstruksi oleh rumus matematika, seperti Font TrueType, Font PostScript juga memungkinkan dilakukan perubahan ukuran, penggambaran karakter dalam berbagai ukuran dan dalam resolusi tinggi. Karakter-karakter disimpan pada tabel bitmap yang merepresentasikan setiap karakter untuk setiap ukuran. PostScript sendiri adalah bahasa pemrograman yang digunakan untuk mengubah instruksi pencetakan grafis yang rumit ke printer digital.

PostScript dikenalkan pada tahun 1984 oleh Adobe. Pada waktu itu terdapat dua tipe Font yang berbeda yaitu tipe 1 dan tipe 3 . Dari kedua tipe tersebut, Tipe 1 merupakan tipe Font yang memiliki format yang lengkap.

\section{Metode Analisis}

Penelitian tentang fungsi kurva bezier dalam pembuatan Font TrueType dan PostScript ini dilakukan dengan cara mengumpulkan beberapa paper dari internet. Selain itu, pengambilan data juga dilakukan dengan mengumpulkan contoh-contoh glyph pada suatu Font beserta titik-titik koordinatnya. Hal ini dilakukan dengan cara membuka file Font TrueType yang berekstensi ttf dan file Font PostScript yang berkekstensi pfb dengan dua program file Font editor berbeda. Penggunaa dua program ini hanyalah ditujukan untuk mempermudah memperoleh data untuk analisis. Batasbatas dalam penelitian ini adalah sebagai berikut :

a. Peran kurva bezier ordo tertentu dalam pembentukan Font TrueType dan PostScript.

b. Analisa titik-titik kurva bezier pada rancangan glyph karakter pada Font TrueType dan PostScript.

c. File-file Font TrueType dan file-file Font PostScript yang hanya berlaku pada sistem operasi Microsoft Windows yaitu file ttf untuk Font TrueType dan file pfb untuk Font PostScript.

d. Font PostScript yang dijabarkan dan dianalisis pada penelitian in hanyalah Font PostScript Tipe 1. 


\section{Prosedur Pengumpulan Data}

Penelitian ini menggunakan prosedur tertentu dalam proses pengumpulan data. Prosedur pengumpulan data pada penelitian ini dijabarkan sebagai berikut :

a. Mencari file-file yang diperlukan pada penelitian ini yaitu file ttf dan file pfb. Hal ini dilakukan dengan mencari file-file kemudian mengunduh tersebut pada web-web internet. Namun pencarian dengan internet tidak perlu dilakukan jika sistem operasi yang digunakan telah memiliki cukup banyak Font untuk dijadikan data. Sebagai keterangan, khusus untuk file berekstensi pfb pencairan dilakukan dengan internet karena Windows tidak menyediakan file-file tersebut.

b. Membuka file -file berekstensi ttf dan pfb dengan program file Font editor yaitu Font Creator Professional Editor 5.6 dan FontLab Studio 5. Kedua program tersebut memiliki perbedaan dalam kapasitas file yang dapat dibuka. Font Creator hanya mampu membuka file-file berekstensi ttf sedangkan FontLab Studio mampu membuka file-file baik berekstensi ttf maupun file berekstensi pfb.

c. Mendapatkan titik-titik koordinat pada glyph karakter untuk setiap contoh file Font baik yang berekstensi ttf dan pfb. Setelah mengetahui titik-titik koordinat yang menunjukkan titik-titik penting pada kurva, langkah selanjutnya adalah mencatat titik-titik tersebut pada sebuah tabel. Setiap tabel hanya mewakili satu glyph karakter pada Font tertentu.

\section{E. Prosedur Penganalisaan Data}

Setelah melakukan pengumpulan data, langakh selanjutnya adalah penganalisaan data. Penelitian ini menggunakan prosedur tertentu dalam proses penganalisaan data. Prosedur penganalisaan data pada penelitian ini dijabarkan sebagai berikut :

a. Menginputkan pada program sederhana beberapa contoh titik yang merupakan bagian kurva pada glyph. Program sederhana merupakan program open source yang didapatkan dari internet yang kemudian dimodifikasi untuk keperluan penelitian ini.

b. Menganalisis gambar kurva yang terbentuk pada program.

c. Mendapatkan gambar kurva pada glyph yang sebenarnya. Hal ini dilakukan dengan cara memperbesar gambar glyph yang merupakan output dari program 
Font editor. Pembesaran gambar difokuskan hanya pada beberapa bagian kurva dari contoh glyph yang sesuai dengan bagian kurva yang diujikan pada program.

d. Membandingkan gambar kurva yang didapatkan dari program dan gambar kurva yang didapatkan dari hasil pembesaran gambar glyph yang sebenarnya.

e. Menyimpulkan perbandingan untuk Font TrueFont dan Font PostScript secara keseluruhan berdasarkan hasil penelitian yang dilakukan.

\section{HASIL PEMBAHASAN}

\section{A. Algoritma De Casetljau}

Tujuan dari algoritma ini adalah menentukan titik tengah dari dua titik terdekat kemudian menyatukan beberapa titik tengah satu sama lain. Berikut ini adalah algoritma singkatnya :

a. Tentukan nilai $\mathrm{t}$ untuk setiap bilangan real dari 0 sampai 1. $t$ adalah bilangan konstan.

b. Tentukan $P_{i}$ untuk setiap nilai t dengan $i=0, \ldots, n$

c. Untuk setiap $\mathrm{j}=0$ lakukan perhitungan rumus kurva bezier.

d. Hubungkan menjadi kurva $g(t)=P[n](t)$.

Berikut adalah gambar dari analisa algoritma de castlejau pada kurva bezier :

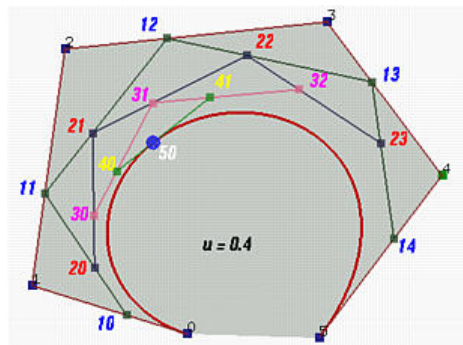

\section{Gambar Analisa algoritma de Casteljau pada kurva bezier}

Pada gambar, nilai t adalah 0,4. 10 merupakan segmen garis dari 00 dan 01, 11 merupakan segmen garis dari 01 dan 02, dan seterusnya hingga 14 adalah segmen garis dari 04 dan 05. Titik-titik baru tersebut diberi nomor dengan ketentuan $1 i$.

\section{B. Font TrueType}

Garis tepi dari sebuah karakter atau biasa disebut glyph dalam Font TrueType dibuat dari bagian-bagian garis lurus dan kurva-kurva kuadratik Bezier. Kurva-kurva matematik yang lebih simpel ini sedikit efisien dalam prosesnya daripada kurva kubik bezier yang lazimnya terdapat pada PostScript dan digunakan pada Font Type 1. 
Meskipun demikian, sebagian besar bentuk membutuhkan lebih banyak titik untuk menggambarkan dengan kurva kuadratik daripada kurva kubik.

TrueType Collection (TTC) adalah ekstensi dari format TrueType yang memungkinkan sejumlah Font dikombinasikan menjadi satu file, menciptakan ruang penyimpanan yang kokoh untuk koleksi-koleksi Font yang hanya menggunakan glyphglyph yang berbeda pada beberapak karakter. Format Font TrueType dasar tersusun dari beberapa tabel yang ditentukan pada header. Sebuah nama tabel dapat tersusun atas 4 kata. Dalam file TTC, mengandung sebuah ttcf tabel yang menyatakan berapa jumlah Font di dalam koleksi. Sejumlah Font di dalam koleksi menggunakan tabel glyph yang sama. Font TrueType regular berekstensi ttf, sementara TrueType Collection berekstensi ttc.

Font TrueType disusun dengan kurva bezier kuadratik. Kurva bezier kuadratik merupakan kurva bezier berordo 2 yang memiliki satu titik off-curve sebagai titik kontrol. Namun ada beberapa area kurva yang memiliki 2 titik off-curve. Hal ini disebabkan oleh dua kurva kuadratik yang saling berurutan sehingga terlihat seperti kurva bezier kubik atau kurva bezier ordo 3 .

Meskipun dipenuhi oleh titik-titik yang berbeda, setiap kontur pada glyph dapat dibagi menjadi beberapa segmen kurva. Setiap segmen kurva diawali dengan titik oncurve dan diakhiri juga dengan titik on-curve. Setiap segmen bisa memiliki 1 titik offcurve maupun 2 titik off-curve. Jika terdapat 2 titik on-curve yang berurutan maka segmen tersebut membentuk kurva bezier linier yang berupa garis lurus.

Perbedaan tempat dari titik-titik kontrol sangat berpengaruh pada tingkat kelengkungan kurva. Jika titik kontrol tidak jauh dari kurva maka kurva terbentuk tidak terlalu melengkung, jika titik kontrolnya terletak lebih jauh dari kurva sehingga kurva yang terbentuk terlihat lebih melengkung.

\section{Font PostScript}

Jika Font TrueType menggunakan kurva bezier kuadratik, glyph-glyph pada Font PostScript digambarkan dengan kurva bezier kubik. Satu set glyph pada Font PostScript dapat diubah-ubah ukurannya melalui transformasi matematika sederhana yang kemudian dapat dikirim ke printer PostScript. Karena data dari Font PostScript khususnya pada Tipe 1 merupakan deskripsi dari garis-garis tepi (outline) dari sebuah glyph maka Font ini juga disebut Font outline. 
Pada sistem operasi Macintosh, Font PostScript terdiri dari file Suitcase dan file Printer. Hanya ada boleh satu file suitcase untuk seluruh keluarga Font yang menyediakan hingga 4 file printer yaitu reguler, italic, bold dan bold italic. Pada sistem operasi Windows, Font PostScript dapat terdiri dari 2 atau 3 file. Satu set 3 file terdiri dari file PFB yang mengandung dara garis tepi, AFM yang mengandung informasi tentang spacing dan kerning, INF yang mengandung informasi tambahan yang berguna untuk instalasi. Selama instalasi berlangsung, dengan program Adobe Type Manager (ATM), Windows menghasilan file PFM yang berbasis pada file AFM dan file INF.

Adobe Type Manager merupakan program yang harus dipasang pada Windows terlebih dahulu sebelum melakukan instalasi Font PostScript. Namun tidak pada semua tipe Windows harus melakukan instalasi ini. ATM dibutuhkan pada sistem operasi Windows 95, 98 NT dan Windows ME. Namun pada sistem operasi Windows 2000, XP dan Vista tidak perlu melakukan instalasi ATM.

File PFB tidak jauh beda denga file TTF. File PFB juga terdiri dari beberapa tabel yang mengandung informasi tersimpan pada header. Glyph-glyphI karakter tersusun pada tabel memiliki informasi sendiri-sendiri. Jumlah glyph juga sangta banyak, bermacam-macam dan berlainan bentuk, sama halnya seperti file TTF pada Font TrueType.

Kurva-kurva bezier pada Font PostScript tidaklah sama dengan kurva-kurva bezier pada Font TrueType karena Font PostScript menggunakan kurva bezier kubik sedangkan Font TrueType menggunakan kurva bezier kuadratik. Selain itu kurva-kurva pada glyph Font PostScript cukup konsisten. Pada glyph Font PostScript, kurva hanya terdiri dari kurva bezier linier yang berupa garis lurus dan kurva bezier kubik yang memiliki 2 titik kontrol.

\section{Perbandingan Font TrueType dengan Font PostScript}

Banyak hal yang telah dijabarkan dan dianalisis menganai kedua Font tersebut sehingga dapat disimpulkan adanya beberapa perbedaan dan persamaan di antara Font TrueType dan Font PostScript.

Persamaan dari kedua Font adalah keduanya sama-sama merupakan Font outline. Glyph-glyph yang dibentuk pada kedua Font tersebut disusun berdasatrkan garis-garis tepi atau kontur yang dibuat berdasarkan kurva matematika. Kurva matematika yang dipakai adalah kurva bezier. Hal ini berlaku untuk keduanya. Jadi 
tidak hanya Font TrueType saja yang menggunakan kurva bezier tetapi juga Font PostScript.

Meskipun keduanya sama-sama menggunakan kurva bezier, jenis kurva bezier yang digunakan pada kedua Font tersebut berbeda. Font TrueType menggunakan kurva bezier kuadratik yang menggunakan 3 titik untuk membentuk kurva, sedangkan PostScript menggunakan kurva bezier kubik yang menggunakan 4 titik untuk membentuk kurva. Perbandingan Font TrueType dan Font PostScript dapat dilihat pada tabel dibawah.

\begin{tabular}{|l|l|l|}
\hline & \multicolumn{1}{|c|}{ Font TrueType } & \multicolumn{1}{c|}{ Font PostScript } \\
\hline Format Font & Outline / Vektor & Outline / Vektor \\
\hline Pengembang & Microsoft dan Apple & Adobe System \\
\hline $\begin{array}{l}\text { Ekstensi file pada } \\
\text { Windows }\end{array}$ & .TTF .PFB dan .PFM \\
\hline Jenis Kurva Bezier & $\begin{array}{l}\text { Kaudratik (ordo 2), } \\
\text { membutuhkan 3 titik yaitu } \\
\text { 2 titik on-curve dan 1 titik } \\
\text { off-curve }\end{array}$ & $\begin{array}{l}\text { Kubik } \\
\text { membutuhkan 4 titik yaitu } \\
\text { 2 titik on-curve dan 2 titik } \\
\text { off-curve }\end{array}$ \\
\hline
\end{tabular}

\section{KESIMPULAN DAN SARAN}

\section{A. Kesimpulan}

Hasil dari penelitian ini dapat disimpulkan sebagai berikut :

1. Font TrueType dan font PostScript merupakan font vektor yang sama-sama menggunakan kurva bezier untuk menggambarkan kontur-kontur glyph.

2. Font TrueType menggunakan kurva bezier kuadratik yaitu kurva bezier berordo 2 yang membutuhkan dua titik yang merupakan titik ujung kurba dan satu titik kontrol.

3. Font PostScript menggunakan kurva bezier kubik yaitu kurva bezier berordo 3 yang membutuhkan dua titik yang merupakan titik ujung kurva dan dua titik kontrol kurva.

\section{B. Saran}

Saran untuk penelitian lanjutan di masa mendatang adalah perlu adanya program yang lebih kompleks dalam penggambaran kurva-kurva bezier sehingga dapat membentuk kontur-kontur glyph secara keseluruhan. 


\section{REFERENSI}

[1] Computer, Apple, Inc. 1993. Inside Macintosh : Text, Addison Weasly.

[2] Prautzsch, Harmut, Wolfgang Boehm, Marco Paluszny, Bezier and B-Spline Techniques, Springer-Verlag Berlin Heidelberg New York, 2002

[3] Solomon, David, Curves and Surfaces for Computer Graphics, Springer Verlag, August 2006

[4] Kennedy, Jhon. A Brief Introduction To Bezier Curves. Mathematics Department. Santa Monica College.

[5] Garfield, Simon. Just My Type : A Book about Fonts, Profile Books LTD ,Great Britain, 2010 